\title{
Preparation of Biodiesel from Sunflower Oil by Transesterification
}

\author{
M. Thirumarimurugan, V. M. Sivakumar, A. Merly Xavier, D. Prabhakaran, and T. Kannadasan
}

\begin{abstract}
The objective is to convert waste sunflower oil used for domestic purposes such as cooking oil into biodiesel using an alkali catalysed transesterification process. Sunflower is one of the leading oil seed crop, cultivated for the production of oil in the world. Biodiesel is gaining more and more importance as an attractive fuel due to the depleting fossil fuel resources. Chemically biodiesel is monoalkyl esters of long chain fatty acids derived from renewable feed stock like vegetable oils and animal fats. It is produced by transesterification in which, oil or fat is reacted with a monohydric alcohol in presence of a catalyst to give the corresponding monoalkyl esters. This article reports experimental data on the production of fatty acid methyl esters from sunflower oil using sodium hydroxide as alkaline catalyst. The variables affecting the yield and characteristics of the biodiesel produced from these vegetable oils were studied. The variables investigated were reaction time $(1-3 \mathrm{~h})$, catalyst concentration $(0.5-1.5 \mathrm{w} / \mathrm{wt} \%)$, and oil-to-methanol molar ratio (1:3-1:9). From the obtained results, the best yield percentage was obtained using a methanol/oil molar ratio of $6: 1$, sodium hydroxide as catalyst $(1 \%)$ and $60 \pm 1{ }^{\circ} \mathrm{C}$ temperature for 1 hour to 3 hours. The biodiesel samples were physicochemically characterized. From the results it was clear that the produced biodiesel fuel was within the recommended standards of biodiesel fuel. It has also been considered as an important crop for biodiesel production. The process involves heating of oil, followed by titration, then settling and separation and finally washing. Base catalyzed transesterification process is applied for optimum yield $(\mathbf{8 0 \%})$ of biodiesel. It was concluded that sunflower oil is one of the option for biodiesel production at a large scale depending on its mass cultivation.
\end{abstract}

Index Terms-Sunflower oil, transesterification, biodiesel.

\section{INTRODUCTION}

Today it is very essential to use alternative fuel because of energy security, environmental concerns and socio-economic reasons [1]. Over the last few years biodiesel has gained importance as an alternative fuel for diesel engines. Manufacturing biodiesel from used vegetable oil is relatively easy and possesses many environmental benefits [2]. The use of vegetable oils as frying oils produces significant amounts of used oils which may present a disposal problem. Their use for biodiesel production has the advantage of their low price. Used vegetable oil is described as a 'renewable fuel' as it does not add any extra carbon dioxide gas to the atmosphere, as opposed to fossil fuels, which cause changes in the atmosphere [3]. From the point of view of chemical reaction,

Manuscript received July 17, 2012; revised October 23, 2012.

The authors are with the Department of Chemical Engineering, Coimbatore Institute of Technology, Coimbatore-641014, India (e-mail: thirumarimurugan@gmail.com,vmsivakumar@gmail.com, merlyxavier10 @gmail.com,dprabhakaran68@gmail.com, tkannadasan56@yahoo.com). vegetable oil from plant sources is the best starting material to produce biodiesel because the conversion of pure triglyceride to fatty acid methyl ester is high and the reaction time is relatively short [2].The most common way to produce biodiesel is by transesterification, which refers to a catalyzed chemical reaction involving vegetable oil and an alcohol to yield fatty acid alky esters (i.e., biodiesel) and glycerol [4] $-[6]$. In the conventional transesterification process, Sunflower seed oils, methanol and $\mathrm{NaOH}$ in various concentrations) were refluxed together in a $500 \mathrm{ml}$ glass reactor equipped with a glass anchor shaped mechanical stirrer, a water condenser and funnel. After the complete conversion of the vegetable oil, the reaction was stopped and the mixture was allowed to stand for phase separation: the ester mixture formed the upper layer and glycerine formed the lower layer [6]. The residual catalyst and unreacted alcohol were distributed between the two phases. After phase separation, using a separatory funnel, the ester mixture was dried over anhydrous sodium sulfate and analyzed by Gas Chromatography.

\section{MATERIALS AND METHODS}

\section{A. Process Conditions}

Pre- heating of oil: $50^{\circ} \mathrm{C}$

Pressure: $1 \mathrm{~atm}$

\section{B. Procedure}

The commencement of the production process depends upon the type of oil employed, and whether it is fresh oil used oils from the catering industry. In the case of the latter, a titration process takes place, the result of which determines the proportions of methanol to potassium hydroxide used in the preparation of the reaction catalyst. The following are the steps required for the production of Bio Diesel:

\section{Titration}

This process is carried out to determine the amount of Potassium hydroxide that would be required. This process is the most crucial and the most important stage of Bio- Diesel manufacturing Titration method for determining how much catalyst needed to neutralize the fatty acids in the used vegetable oil.

- Dissolve 1 gram of $\mathrm{KOH}$ in 1 liter of distilled water.

- Dissolve $1 \mathrm{ml}$ of waste vegetable oil into $10 \mathrm{ml}$ isoprophyl alcohol.

- With an eyedropper, set the pH of WVO to 8-9 by adding $\mathrm{NaOH}$ one milliliter at a time. You will see an eventual rise in the ph level. 
- Record the quantity of $\mathrm{KOH}$ solution added until the colour of the oil changes pink and holds for at least 5 seconds (This represents a $\mathrm{pH}$ of between 8 and 9).

\section{Titration to Determine the Excess Catalyst}

- Burette solution: $\mathrm{KOH}$ solution -1000ppm

- Pipette solution: $1 \mathrm{ml}$ of used vegetable

- Solvent: $10 \mathrm{ml}$ iso propyl alcohol

- Indicator: Phenolphthalein.

- End point: Appearance of pink color

\section{E. Preparation of Potassium Methoxide}

- Carefully pour the $\mathrm{KOH}$ solution into $100 \mathrm{ml}$ methanol.

- Agitate the mixture until the $\mathrm{KOH}$ is completely dissolved in the methanol.

\section{F. Heating and Mixing}

The potassium methoxide solution prepared is mixed with oil. The residue is heated in between $120{ }^{\circ} \mathrm{F}$ to $130{ }^{\circ} \mathrm{F}$ after which it is mixed well using a stirrer at $300 \mathrm{rpm}$.

- Continue mixing the contents.

- Carefully pour the potassium methoxide and shake vigorously for 15 minutes.

\section{G. Settling and Separation}

After mixing the liquid, it is allowed to cool down. After the cooling process, the bio fuel is found floating on the top while the heavier glycerine is found at the bottom. The glycerine is easily separated by allowing it to drain out from the bottom. In this way pure Bio Diesel is prepared [7].

- Allow the glycerin to settle

- Settle the mixture overnight.

- The successful chemical reaction between the oil, alcohol, and the catalyst will have broken down the oil into several layers.

- The top layer will be biodiesel, chemically called an Ester, the next layer may contain soap, and the bottom layer will be glycerine

\section{H. Washing}

Biodiesel and glycerin will separate due to density difference. Glycerin and unreacted catalyst will sink to the bottom and can be easily drained [8].After separation of biodiesel it must be washed with hot water to remove unreacted methanol and potassium hydroxide [9]-[13].

\section{Filtration}

In this process, the waste vegetable oil is filtered to remove all the food particles. This process generally involves warming up the liquid a little. After warming up the liquid, it is filtered with the use of a cotton cloth.

\section{J. Removing Water}

All the water contained in the residual gangue is removed which makes the reaction faster. The water is easily removed by boiling the liquid at $50^{\circ} \mathrm{C}$ for some time.

\section{K. Fuel Properties Analysis}

Fuel properties analysis was carried out according to
ASTM Biodiesel Standards. Fuel characteristics of biodiesel which were tested include dynamic viscosity at $40^{\circ} \mathrm{C}$ (eta), kinematic viscosity at $40^{\circ} \mathrm{C}$ (ny), density at $40^{\circ} \mathrm{C}$ (Rho), , flash point $\left({ }^{\circ} \mathrm{C}\right)$, cloud point $\left({ }^{\circ} \mathrm{C}\right)$, specific gravity at $60^{\circ} \mathrm{F}$ $(\mathrm{kg} / 1)$, Carbon residue, Acid value and Calorific value.

TABLE I: INSTRUMENTS USED TO DETERMINE THE PROPERTIES OF OIL.

\begin{tabular}{|c|c|}
\hline Property & Instrument \\
\hline Density & Specific gravity bottle \\
\hline Viscosity & Oswald viscometer \\
\hline Cetane index & ASTM D 613 \\
\hline Cloud point & ASTM D 2500 \\
\hline Flash point \& fire point & Pensky-marten apparatus \\
\hline Carbon residue & ASTM D 4530 \\
\hline Acid value & Titration \\
\hline
\end{tabular}

TABLE II: EXPERIMENTAL VALUES.

\begin{tabular}{|c|c|c|c|c|}
\hline & Property & $\begin{array}{l}\text { Standard } \\
\text { value }\end{array}$ & $\begin{array}{l}\text { Experimental } \\
\text { value }\end{array}$ & Units \\
\hline 1 & Density & 0.87 & 0.68 & $\mathrm{~g} / \mathrm{cc}$ \\
\hline 2 & $\begin{array}{l}\text { Kinematic } \\
\text { Viscosity }\end{array}$ & $1.9-6.5$ & 6 & $\mathrm{~mm}^{2} / \mathrm{s}$ \\
\hline 3 & $\begin{array}{l}\text { Cetane } \\
\text { number }\end{array}$ & $>47$ & 48 & $\begin{array}{c}\text { No } \\
\text { units } \\
\end{array}$ \\
\hline 4 & $\begin{array}{l}\text { Carbon } \\
\text { Residue } \\
(100 \% \\
\text { sample) }\end{array}$ & 0.050 & 0.15 & $\mathrm{Wt} \%$ \\
\hline 5 & Acid number & $0.50(\max )$ & 0.36 & $\begin{array}{c}\mathrm{mg} \\
\mathrm{KOH} / \mathrm{g}\end{array}$ \\
\hline
\end{tabular}

\section{Economics of the Process}

- Cost of $1000 \mathrm{ml}$ of use vegetable oil= Rs.20

- Cost of $200 \mathrm{ml}$ of Methanol= Rs.15

- Cost of Potassium hydroxide= Rs.3

- Total cost $=$ Rs.38

\section{RESUlTS AND CONCLUSION}

Thus Bio Diesel was prepared from used vegetable oil, the properties resembled closely to that of commercial Diesel. Hence it can be used as an alternate for diesel. It is relatively economic than diesel and emits less pollutants. It can be used for Vehicular use, Railway usage, as heating oil when blended with other fuel oil in proportion. The experimental work carried out in this project shows that bio-diesel of acceptable quality can be produced on a small scale from a number of low-cost raw materials. However, the search for alternative feed-stocks needs to be continued. More research on the esterification of used vegetable oil is needed, to establish process requirements for high yield and quality, and to find ways of improving its low-temperature properties so that a higher proportion could be included in bio-diesel blends. The ester yields obtained from all the oils used in these trials have been low in comparison with those obtained from refined vegetable oils in existing large-scale plants. Rising of yields has a significant effect on the economics of bio-diesel production. Modern technology is giving very high yields; it needs to be demonstrated that the same can be achieved with other raw materials, whereas more information is required on alternative uses for small amounts of glycerol. On this scale, the investment required to produce pharmaceutical grade 
glycerine could not be warranted. Uses that require a minimum amount of additional plant investment, but add maximum value to the produce, need to be examined. When a use for the glycerol has been decided a plant for the removal of methanol and any further processing of the glycerol can be specified. In this work, biodiesel was prepared using alkali catalyzed method where the raw material used was waste sunflower oil used for cooking. Biodiesel can also be manufactured using non-edible oil such as pongamia oil as raw material. Further studies can also be carried out by modifying the catalysis. i.e. by using either acid-base or algae as the catalyst.. Increased utilization of renewable bio fuels results in significant microeconomic benefits to both the urban and rural sectors, and the balance of trade. The chief advantage of Biodiesel for agriculture is cost minimisation. The expression "oil well on your farm" means in fact a higher local value added. Oil plants renew themselves every year. In any event, the focus is not only on providing emergency supplies but also to a large extent on reducing the pollution load produced by day-to-day operations. The flexibility of Biodiesel plants is also a response to another energy target: the creation of manageable regional supply systems. The production of biodiesel is relevant for developing countries where the demand of transport fuels is going to increase to a great extent. A high-quality research is promoted in support of a sustainable development of society covering subjects of strategic importance to economic and social development and aiming a greater energy self-sufficiency and security in addition to environmental (decreasing the air pollution from transportation and mitigating greenhouse gas emissions) benefits. The biodiesel fuel production has gained importance for its ability to replace fossil fuels, its environmental benefits and the fact that it is a renewable source of energy. Since the direct usage of vegetable oils as biodiesel is impractical, many processes have been developed to convert them into a suitable form. Pyrolysis and microemulsification are not satisfactory and hence only the transesterification process is accepted for large scale production of biodiesel.

\section{REFERENCES}

[1] A. B. M. S. Hossain and A. N. Boyce, Biodiesel Production from Waste Sunflower Cooking Oil as an Environmentally Recycling Process and Renewable Energy, pp. 312-316, 2009.

[2] M. Allen, Straighter Than Straight Vegetable Oils, pp. 345-356, 2002.

[3] K. Kalisanni, K. Khalizani, and M. S. Rohini, Analysis of Waste Cooking Oil a Raw Material for Biofuel Production, pp. 82-83, 2008

[4] Anon, A Diesel Replacement Fuel, pp. 315-318, 1997.

[5] P. Calais and A. R. Clark, "Waste vegetable oil as alternate fuel," Frohlich, A. \& Rice, B., vol. 1995, 2004.

[6] A. B. M. S. Hossain, A. N. Boyce, A. Salleh, and Chandran, "Bio Diesel Production from Waste Soyabean Oil Biomass as Renewable Energy and Environmental Recycled Process, pp. 4323-4240, 2010.

[7] C. V. Sudhir, N. Y. Sharma, and Mohanan, Potential of Waste Cooking Oil as Bio Diesel Feed Stock, pp. 69-72, 2007.

[8] M. Mathiyazhagan, A. Ganapati, B. Jaganath, N. Renganayaki, and N. Sasireka, Production of Biodiesel from Non-Edible Plant Oils Having High FFA Content, pp. 119-122, 2011.

[9] "The preparation and properties of bio-diesel grade methyl ester from waste cooking oil," in Proc. Minutes of the Activity Meeting of the IEA, Vienna, November, pp. 11-18, 1995.

[10] M. Mittelbach, "The high flexibility of small scale biodiesel plants production of methyl esters in high quality using various feedstocks," in Proc. European Motor Biofuels Forum, Graz, pp. 183-187, Sept 22-25, 1996

[11] M. Mittelbach, The High Flexibility of Small Scale Bio-Diesel Plants, 1996

[12] V. Kraftstoffe, "Coconut oil and coconut oil ethanol derivatives as fuel for diesel engines," University of the South Pacific, Fiji Islands, pp. 194-198, 1997.

[13] G. Vaitilingom et al., "Crude cannola oil, a biofuel for diesel engines," New Caledonia, pp. 26-28, 1995.

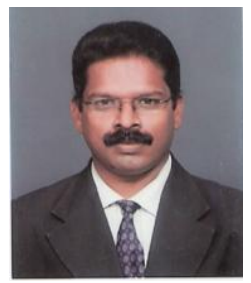

M. Thirumarimurugan was born in Tamil Nadu, India. He has completed his B.Tech. and M.Tech. degrees in Chemical Engineering from Bharathiar University, Coimbatore in 1995 and 1997 respectively. He pursued his Ph.D. degree in Heat Transfer from Anna University Chennai, Chennai He has 17 years of teaching experience and currently holds the post of Associate professor in Department of Chemical Engineering, at Coimbatore Institute of Technology, Coimbatore. He has authored One book, 13 International journals, 3 National journals, 51 conference proceedings. He has guided 16 PG projects, 22 UG projects, 4 mini projects and he is currently guiding 5 $\mathrm{Ph}$. D research projects. He has also organized 6 Conferences, short-term courses. He has attended 26 conferences, summer/winter school, QIP courses and Workshops. Dr. M. Thirumarimurugan is a Life Member in II Ch. E and a Member in Indian Society for Technical Education. He got II best paper award in Energy and Environment in National Conference.

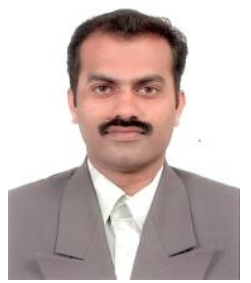

V. M. Sivakumar received his B.E. degree (Chemical Engineering) from Annamalai University in 1998, India. Further, his M.Tech. degree (Chemical Engineering) degree from Bharathiar University, India in 2000 and pursued his Ph.D. degree (Chemical Engineering) at Universiti Sains Malaysia (USM), Malaysia (2007 - 2010). He joined Coimbatore Institute of Technology (CIT) as a Lecturer in the Department of Chemical Engineering in the year 2000 and at present as Assistant Professor in Chemical Engineering. His area of research are Catalysis and Reaction Engineering, Environmental Engineering, Nanomaterials and Nanotechnology. One of his priority research areas is to conduct fundamental studies in developing effective catalysts for growing carbon Nanotubes (CNTs) from natural gas. His research outcomes has got published in leading peer-reviewed Journals like Materials Letters, Journal of Nanomaterials, Chemical Papers, Reviews on Advanced Materials Science, etc. He is the Member of Asia Pacific Chemical, Biological and Environmental Engineering Society (APCBEES), Life member of Indian Institute of Chemical Engineers.

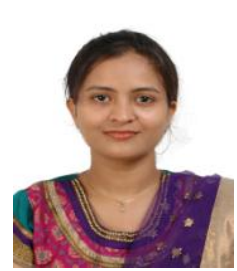

A. Merly Xavier was born in Tamil Nadu, India. She is an undergraduate student doing her final year B.Tech. degree in Chemical Engineering from Institute of Technology, Coimbatore. Her area of interest includes Heat transfer and Chemical Reaction Engineering. She has presented papers in CHEMCON 2011. She has also presented more than 5 oral papers. Ms. Merly Xavier is a member of II Ch E.

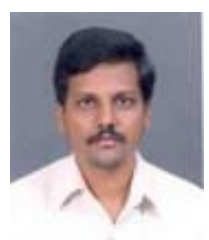

D. Prabhakaran was born in Tamil Nadu, India. He has completed his B.Tech. degree in Chemical Engineering from Bharathiar University, completed M.Tech. degree in Chemical Engineering from Bharathiar University, completed his M.B.A. degree from Madurai Kamaraj University and was awarded the Ph.D. degree in Chemical Engineering from Anna University Coimbatore. His area of specialization at Undergraduate course is Environmental Engineering and Management, Process Engineering Economics, Process Dynamics Instrumentation and Control and for Post graduate course is Advanced Process Dynamics and Control, Fluidization Engineering. He has 20 years of teaching experience. He is currently the Associate Professor, Department of Chemical Engineering, Coimbatore Institute of Technology Coimbatore, Tamil Nadu. He has presented papers in more than 20 National and International Conferences and guided a number of Projects for M.Tech and B.Tech and also published more than 10 papers in National and International Journals UK, Taylor \& Francis Group publications, March 2010; International Journal of Environmental Science 
and Technology, New York, Springer publications, 2009;etc. Dr. D. Prabhakaran, is a Life member of Indian Institute of Chemical Engineers and Indian society of Technical Education, and a Member of Asia Pacific Chemical, Biological and Environmental Engineering Society (APCBEES).

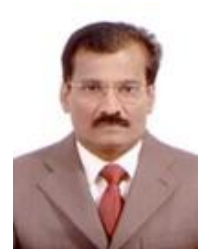

T. Kannadasan was born on 12-6-1955 in Madurai, Tamil Nadu, India. He has completed his B.E. degree in Chemical Engineering from Annamalai University, Chidambaram, completed M.Tech. degree in Chemica Engineering from University of Madras, Chennai and was awarded the Ph.D. degree in Chemical Engineering from Annamalai University, Chidambaram. He has served as Management Trainee at M/s Gangappa Paper Mills Ltd., From.He has served in various Capacities from Associate
Lecturer to Assistant Professor in Coimbatore Institute of Technology, Coimbatore, as Professor (PG Course) in Chemical Engineering at Coimbatore Institute of Technology, Coimbatore. He has served the post of Controller of Examinations-Additional charge University Departments of Anna University of Technology, Coimbatore. Currently he is the Professor and Head of Chemical Engineering Department at Coimbatore Institute of Technology, Coimbatore, Tamilnadu, India. He has guided 20 M.Tech. Thesis in various areas of chemical engineering. He has guided 13 $\mathrm{Ph}$. D thesis out of which 8 are completed and 5 are still going on. Dr. T. Kannadasan is a Life member of Indian Institute of Chemical Engineers(II Ch. E), Indian Society for Technical Education and The Institution of Engineers (India), senior member of Asia Pacific Chemical and Biological \& Environmental Engineering Society (APCBEES). 